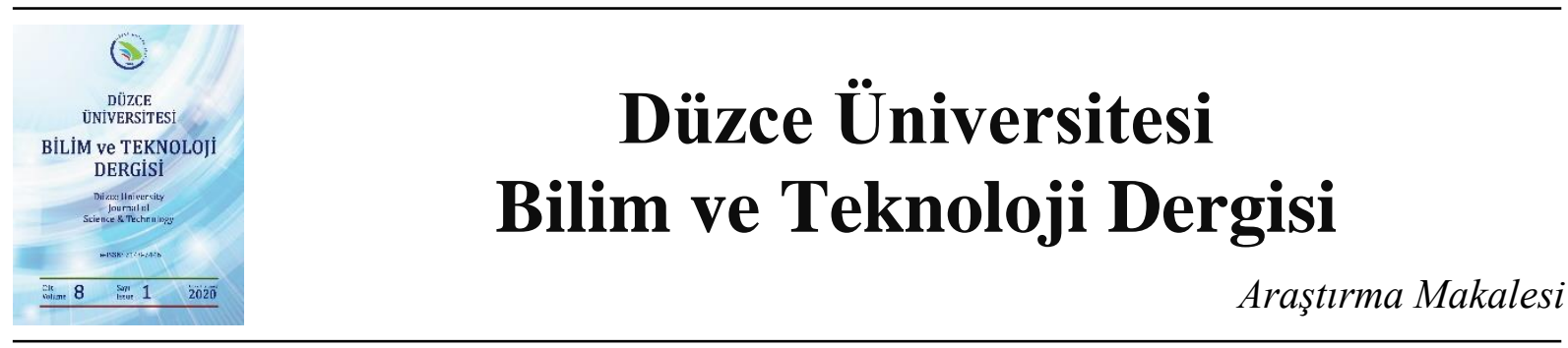

\section{Tekrarlı Ortalama Yardımıyla Renk İndirgeme ve Görüntü Erişimi}

\author{
Mahmut KILIÇASLAN ${ }^{\mathrm{a},{ }^{*} \text {, (D) Ufuk TANYERİ }}{ }^{\mathrm{a}}$, (D) Recep DEMİRCi ${ }^{\mathrm{b}}$ \\ ${ }^{a}$ Bilgisayar Teknolojileri Bölümü, Nallıhan Meslek Yüksekokulu, Ankara Üniversitesi, Ankara, TÜRKIYE \\ ${ }^{b}$ Bilgisayar Mühendisliği Bölümü, Teknoloji Fakültesi, Gazi Üniversitesi, Ankara, TÜRKIYE \\ * Sorumlu yazarın e-posta adresi: m.kilicaslan@ankara.edu.tr
}

DOI : 10.29130/dubited.643351

\begin{abstract}
ÖZET
Sayısal görüntülerden oluşan bir veri tabanından sorgulanan bir görüntünün aynısının veya benzerlerinin getirilmesi süreci görüntü erişimi olarak tanımlanır. Her ne kadar sayısal görüntü piksellerden oluşuyor olsa da sorgulama piksel düzeyinde değil, sayısal görüntüleri temsil eden vektörler düzeyinde yapılmaktadır. Görüntülerin vektörler ile temsil edilmesi özellik çıkarma süreci olarak adlandırılır ve içerik tabanlı görüntü erişiminin (ITGE) en önemli aşamasıdır. Özellik vektörünün temsil kabiliyetinin düşük olması sistemin performansının da düşük olması demektir. Gri ölçekli görüntülerin histogramları en tipik özellik vektörleridir. Diğer taraftan renkli görüntülerde üç ayrı kanal mevcut olduğundan, görüntüyü temsil edebilecek histogram üç boyutlu bir dizi oluşturur ki bu durum sistemin hesap maliyetini oldukça artıracaktır. Bu nedenle araştırmacılar renkli görüntülerdeki renk sayısını azaltma veya renk indirgeme yaklaşımını tercih etmişlerdir. Vektör kuantalama olarak adlandırılan renk indirgeme sürecinde ise her zaman aynı sonucu üretmek mümkün olmamıştır. Bunun nedeni ise bazı algoritmaların başlangıçta rastgele üretilen renk vektörleri ile çözüm aramalarıdır. Linde-Buzo-Gray (LBG), K-ortalamalar ve bulanık c-ortalamalar algoritmaları bu tür çözüm yaklaşımlarına tipik örneklerdir. Bu çalışmada tekrarlı ortalama tabanlı renk indirgeme yaklaşımı kullanılarak yeni bir görüntü erişim metodu önerilmiştir. Önerilen stratejide, öncelikle her bir renk kanalının histogramı üzerinden tekrarlı bir şekilde ortalamalar hesaplanmış ve çok seviyeli eşikler elde edilmiştir. Elde edilen eşikler kullanılarak RGB renk uzayı alt prizmalar şeklinde dilimlenmiştir. Oluşan alt prizmalar içinde kalan pikseller aynı sınıfa atanmış ve ilgili sınıftaki piksellerin ortalamaları kullanılarak renk indirgemesi yapılmıştır. Sınıf indisleri ve ilgili sınıflara tahsis edilen piksel sayıları yardımıyla tek boyutlu histogram elde edilmiştir. Son aşamada ise elde edilen sınıf tabanlı histogram özellik vektörü olarak atanmış ve içerik tabanlı görüntü erişimi gerçekleştirilmiştir. Önerilen algoritma ve LBG algoritması ile sonuçlar alınmış ve karşılaştırmalar yapılmıştır.
\end{abstract}

Anahtar Kelimeler: Görüntü Erişsimi, Tekrarlı Ortalama, Çok Seviyeli Eşikleme, Renk Indirgeme

\section{Color Reduction with Recursive Mean and Image Retrieval}

\begin{abstract}
Image retrieval is defined as the process of retrieving same or similar of an image queried from a digital image database. Although a digital image is composed of pixels, the query is not performed at the pixel level but it is carried out at level of vectors representing digital images. In other words, it is computationally necessary to represent with vectors both queried image and images in database. The similarity between queried and database images is computed by vector operations. The representation of images by vectors is called feature extraction process and it is the most significant stage of content-based image retrieval (CBIR). Histograms of gray scale images are typical feature vectors. On the other hand, as there are three different channels in color images, the
\end{abstract}


histograms which represent images are three-dimensional arrays, which will increase the computational cost of the system considerably. For this reason, researchers have preferred to use color quantization or reduce the number of colors in color images. The color reduction process is called as vector quantization, but it is not always possible to produce the same result. The reason is that the developed algorithms so far look for solutions with randomly generated color vectors initially. Linde-Buzo-Gray (LBG), K-means and fuzzy c-means algorithms are typical examples of such solution approaches. In this study, a new image retrieval method has been proposed by using the recursive mean-based color reduction approach. In the proposed strategy, firstly, averages were calculated from the histogram of each color channel and consequently multi-level thresholds were obtained. Using the thresholds obtained, RGB color space was sliced into sub-prisms. The pixels in the created sub-prisms were assigned to the same class and color reduction was made by using the means of pixels in the related class. One-dimensional histogram was obtained with the help of class indices and the number of pixels allocated to the related classes. In the last stage, the obtained class-based histogram was assigned as feature vector and content-based image retrieval was performed. The results were obtained with the proposed algorithm and LBG algorithm. Additionally, comparisons were made.

Keywords: Image Retrieval, Recursive Mean, Multi-Level Thresholding, Color Reduction.

\section{GiRiș}

Teknolojinin gelişmesiyle birlikte sayısal görüntülerin kalitesi ve kullanımı bir hayli artmıştır. Tıp, adli bilişim, savunma ve güvenlik gibi birçok alanda görüntü işleme vazgeçilemez bir süreç olmuştur. Uygulama alanlarının ve miktarlarının artması büyük veri yığınlarının oluşmasına neden olduğundan, istenilen görüntüye erişmek önemli bir problemdir. Böylece görüntü erişimi yoğunlaşılan bir alandır ki yapılan araştırmalar görüntü yığınları içerisinden istenilen doğru görsele hızlı bir şekilde ulaşmayı amaçlamaktadır. Söz konusu hedeflere ulaşmak adına 1970'lere kadar metin tabanlı yaklaşımlar geliştirilmiştir [1]. İlgili teknikler, görsel içeriklerin kelimelerle eşleştirilerek indekslenmesine dayanmaktadır. Ancak metin tabanlı görüntü erişiminin iki dezavantajı vardır. İlki görüntüleri metinlerle ifade etmek için yoğun bir insan gücüne ihtiyaç duyulmasıdır. İkincisi ise, insan algısının öznelliği nedeniyle aynı görüntüler için farklı kelimelerin tercih edilmesidir [2,3]. Bahsedilen dezavantajların üstesinden gelmek için 1980'li yıllarda içerik tabanlı görüntü erişimi (ITGE) çalışmaları başlamıştır. İçerik terimi görüntünün renk, şekil, doku veya bunların birleşimden oluşan özellik vektörü şeklinde tanımlanabilir. İTGE yaklaşımları özellik çıkarımı, benzerlik ölçümü ve performans değerlendirme olmak üzere üç aşamadan meydana gelmektedir [4-6]. Özellik çıkarımı İTGE'nin en önemli basamağıdır. Görüntüden çıkarılan özelliklerin ilgili görüntüyü temsil edebilme kabiliyeti sistemin performansını doğrudan etkilemektedir. Ayrıca özelliklerin vektörel büyüklüğü, hesapsal karmaşıklık bakımından son derece önemlidir. Bundan dolayı yapılan çalışmalar en kısa sürede en doğru görüntüye erişimi sağlayacak özellik çıkarımlarına odaklanmıştır. Yerel doku yaklaşımları, kenar tanımlayıcıları, dalgacık ve Fourier dönüşümü [7-10] gibi teknikler şekil ve doku özelliklerinden yararlanmaktadır. Renk tutarlılığı vektörü [11], renk momentleri [12], baskın renk tanımlayıcıları [13] gibi algoritmalar ise özellik çıkarımı aşamasında renk özelliği kullanan tekniklerden bazılarıdır. Lee ve Nang çalışmalarında yerel bölge özelliklerine bakarak içerik tabanlı görüntü erişimi geliştirmişlerdir. Çalışmalarında alt bloklara ayrılan görüntülerde kullanıcının belirlediği bölgelerde baskın renk özelliğinden faydalanmışlardır. Ancak kullanıcı müdahalesi yöntemin en belirgin dezavantajıdır [14]. Zhao ve arkadaşları ise maksimum entropi prensibine dayanan geometrik desen özellikleri çıkarmışlardır. Ancak taç noktalar ile oluşan desenler iteratif işlemler ile elde edilmektedir [15]. Ashraf ve arkadaşları diğer çalışmadaki gibi özellik olarak geometrik bir desen oluşturmuşlardır. Yaklaşımlarında Bandelet dönüşümü, yapay sinir ağı ve Gabor filtresi ile çıkarılan özellik, RGB-YCbCr dönüşümü, Canny kenar operatörü ve ayrık dalgacık dönüşümünden gelen özellik ile birleştirilmiş̧ir [16]. Uygulamalarındaki ön-işlemler, hesapsal karmaşıklığı artırmaktadır. Lu ve diğerleri de HSV renk uzayını kullanmışlardır. Çalışmalarında entropi ve ilişkili geri bildirim tabanlı bir İTGE yöntemi 
önermişlerdir. Geliştirdikleri teknik çoklu-özelliğin farklı benzerlik ölçümleri ile iteratif olarak ağırlıklandırmasıyla tek bir özelliğe dönüştürülmesi prensibine dayanmaktadır [17]. Yukarıda bahsedilen şekil ve doku tanımlayıcılarının yanı sıra renk bilgisi de etkili bir özellik olarak kullanılmıştır.

Basit, etkili ve sıklıkla başvurulan [18] histogram görüntüleri renk seviyeleri ve onların sayısı ile ifade eden global bir temsil aracıdır. İlgili dağılım aracılığıyla görsellere ait içeriksel tanımlar yapılmaktadır. Gri seviyeli görüntülerde histogram tek boyutlu bir vektör ile ifade edilirken, renkli görsellerde ise üç boyutlu bir matrisin çözümlenmesini gerektirmektedir. İlaveten her kanaldan alınan histogram bilgisinin birleștirilmesi de ayrı bir problemdir. RGB renk modelinde 224 renk bilgisi bulunmakta ve geliştirilecek tekniklerin hesapsal karmaşıklığı artmaktadır. Bu nedenle etkili bir görüntü erişimi için renk indirgeme yaklaşımlarına ihtiyaç duyulmaktadır. Renk indirgeme işlemi benzer renklerin aynı grup [19] altında toplanması olarak tanımlanabilir. LBG de renk indirgemesi için sık kullanılan bir yaklaşımdır [20]. Bununla birlikte LBG algoritması kümeleme, hızlı arama, görüntü sıkıştırma ve İTGE sistemi gibi çeşitli işlemlerde de kullanılmaktadır. LBG algoritması başlangıç küme merkezlerini rastgele belirleyen iteratif bir yaklaşım olup, her seferinde aynı sonucun alınmasını garanti etmeyen bir yaklaşımdır.

Bu çalı̧̧mada yeni bir renk indirgeme algoritması önerilmiştir. Geliştirilen yöntem LBG'nin aksine herhangi bir başlangıç değerine ya da durdurma eşiğine ihtiyaç duymamaktadır. İlaveten iteratif değildir. Önerilen yöntem renkli görüntülerin tekrarlı ortalama ile çok seviyeli olarak eşiklenmesini temel almaktadır. Geliştirilen stratejide öncelikle her bir renk kanalının histogramı üzerinden tekrarlı bir şekilde ortalamalar hesaplanmış ve çok seviyeli eşikler elde edilmiştir. Elde edilen eşik değerleri aracılığıyla RGB renk uzayı prizmalara bölünmüştür. Bölünen alanlardaki pikseller ise aynı sınıfa atanarak sınıflandırma işlemi yapılmaktadır. İlaveten aynı kümedeki tüm piksellere ilgili sınıftaki piksellerin ortalama değerleri atanmış ve renk indirgemesi yapılmıştır. Böylelikle renkli görüntüler için üç farklı renk kanalından gelen bilgiler tek bir vektörde birleştirilerek yeni bir özellik oluşturulmuştur. Aynı sınıfta bulunan piksellerin dağılımı ile de sınıfsal tabanlı tek boyutlu histogram elde edilmiştir. Son aşamada ise sınıfsal tabanlı histogram bilgisi özellik vektörü olarak kullanılarak görüntü erişimi gerçekleştirilmiştir. Tüm deneyler Corel1 $\mathrm{K}$ veri seti üzerinde uygulanmış ve geliştirilen yöntem LBG tabanlı görüntü erişimi ile karşılaştırılmıştır.

\section{RENK İNDIRGEME}

Renk indirgeme, kümeleme ve sıkıştırma işlemlerinde kullanılan bir vektör nicemleme tekniğidir. Vektör nicemleme bir veri setinin daha az sayida eleman ile temsil edilmesidir. Söz konusu tekniğin renkli görüntülerde uygulaması ile piksel çeşitliliği azaltılmaktadır. Dolaysıyla bilgi kaybı kaçınılmazdır. Renk indirgeme yaklaşımlarının başarısı indirgenen görüntünün orijinalini temsil etme başarısı ile ölçülmektedir. LBG vektör nicemleme yöntemi sıklıkla tercih edilen bir tekniktir. İteratif bir yaklaşım olan LBG algoritması, $d$ boyutlu vektörlerden oluşan bir girdi verisini, $B=\left\{b_{i} \in R^{d} \mid i=1,2, \ldots, n\right\}$ benzerlik kriterleri kullanarak K elemanlı bir $C=\left\{c_{j} \in R^{d}, K<n \mid j=1,2, \ldots, K\right\}$ vektör kümesine dönüştürür. LBG tekniği aşağıdaki aşamalardan oluşmaktadır:

Adım 1: $B$ giriş vektörünü al,

Adım 2: Küme başlangıç merkezlerini rastgele oluştur,

Adım 3: Bozulum miktarını, $D_{r}=0$ ve iterasyon sayısını sıfırla, $r=0$,

Adım 4: Ĕger $\left\|b_{i}-c_{j}\right\| \leq\left\|b_{i}-c_{q}\right\| j \neq q$ ise giriş elemanını $S_{j}$ bölgesine dâhil et,

Adım 5: $c_{j}=\frac{1}{\left|S_{j}\right|} \sum_{b_{i} \in S_{j}} b_{i}$ eşitliğine göre küme merkezlerini güncelle,

Adım 6: Bozulum miktarını hesapla $D_{r}=\sum_{j=1}^{K} \sum_{b_{i} \in S_{j}}\left\|b_{i}-c_{j}\right\|$ 
Adım 7: Ĕger $\frac{D_{r-1}-D_{r}}{D_{r}}>\varepsilon$ ise 4. adıma git

Adım 8: Değilse çıktı vektör kümesini oluştur.

Yineleme işlemi daha önceden belirlenen bir duruma kadar devam etmektedir. Dr bozulum miktarı her iterasyonda hesaplanmaktadır. Söz konusu yöntemde küme sayısı $\mathrm{K}$ ve durdurma eşiği $\varepsilon$ kullanıcı tarafından belirlenmektedir. Küme merkezlerinin başlangıçta rastgele seçilmesi yaklaşımın en temel dezavantajidir.

\section{Tekrarli Ortalama Tabanli Cok Seviyeli Eșíleme}

Eşikleme, görüntünün histogram bilgisini temel alarak görüntüyü ayrıştırmayı amaçlayan bir işlemdir. Ancak çok seviyeli eşikleme için istenilen eşik değerleri bulmak zahmetli bir süreçtir. Bu amaçla Demirci ve Okur [21] çok seviyeli eşikleri tespit etmek için eşik sayısı kadar tekrarlı ortalama hesaplaması yapan bir yaklaşım önermişlerdir. Önerilen çalışmada histogram bilgisi kullanılarak kısmi olasılık dağılımlarının toplamı ve kısmi ortalamalardan yararlanılmıştır. Gri seviyeli görüntülerde, pikseller $\{0,1,2, \ldots, L\}$ değerlerini almaktadır ve $\mathrm{L}=255$ maksimum gri seviyesini göstermektedir. Böylece bir pikselin i. seviyede bulunma olasılı ğ1,

$$
p_{i}=h_{i} /(M x N)
$$

şeklinde hesaplanmaktadır. Burada $i$ renk seviyesini, $h_{i} i$. seviyeye ait piksel sayısını ve $M$ ve $N$ görüntü boyutlarını göstermektedirler. Kısmi olasılık dağılımlarının toplamı $\omega_{0}, \omega_{1}, \omega_{00}, \omega_{01}, \omega_{10}, \omega_{11}$ ve kısmi ortalamalar $\mu_{0}, \mu_{1}, \mu_{00}, \mu_{01}, \mu_{10}, \mu_{11}$ sirasiyla;

$$
\begin{array}{ll}
\omega_{0}=\sum_{i=0}^{\mu_{T}-1} p_{i}, \quad \mu_{0}=\sum_{i=0}^{\mu_{T}-1} \frac{i p_{i}}{\omega_{0}} \\
\omega_{1}=\sum_{i=\mu_{T}}^{255} p_{i}, \quad \mu_{1}=\sum_{i=\mu_{T}}^{255} \frac{i p_{i}}{\omega_{1}} \\
\omega_{00}=\sum_{i=0}^{\mu_{0}-1} p_{i}, \quad \mu_{00}=\sum_{i=0}^{\mu_{0}-1} \frac{i p_{i}}{\omega_{00}} \\
\omega_{01}=\sum_{i=\mu_{0}}^{\mu_{T}-1} p_{i}, \quad \mu_{01}=\sum_{i=\mu_{0}}^{\mu_{T}-1} \frac{i p_{i}}{\omega_{01}} \\
\omega_{10}=\sum_{i=\mu_{T}}^{\mu_{1}-1} p_{i}, & \mu_{10}=\sum_{i=\mu_{T}}^{\mu_{1}-1} \frac{i p_{i}}{\omega_{10}} \\
\omega_{11}=\sum_{i=\mu_{1}}^{255} p_{i}, & \mu_{11}=\sum_{i=\mu_{1}}^{255} \frac{i p_{i}}{\omega_{11}} \\
\mu_{T}=\sum_{i=0}^{L-1} i p_{i} &
\end{array}
$$


olarak tanımlanmıştır. Anlaşılacağı üzere her bir aşamada bir öncekinden elde edilen eşik değerlerden yararlanılmaktadır. Tablo 1 tekrarlı ortalama metodu ile edilen eşikleri ve atanan değerleri göstermektedir.

Tablo 1. Eşik sayıları ve değerleri

\begin{tabular}{cc}
\hline Eşik sayısı (t) & Atanan değerler \\
\hline$t_{1}$ & $\mu_{\mathrm{T}}$ \\
$\mathrm{t}_{1} \mathrm{t}_{2}$ & $\mu_{0} \mu_{1}$ \\
$\mathrm{t}_{1} \mathrm{t}_{2} \mathrm{t}_{3}$ & $\mu_{0} \mu_{\mathrm{T}} \mu_{1}$ \\
$\mathrm{t}_{1} \mathrm{t}_{2} \mathrm{t}_{3} \mathrm{t}_{4}$ & $\mu_{00} \mu_{01} \mu_{10} \mu_{11}$ \\
$\mathrm{t}_{1} \mathrm{t}_{2} \mathrm{t}_{3} \mathrm{t}_{4}$ & $\mu_{00} \mu_{01} \mu_{\mathrm{T}} \mu_{10} \mu_{11}$ \\
\hline
\end{tabular}

\section{RENK UZAYININ BölüMLENMESI VE TEK BOYUTLU HístOGRAM}

Histogram, görüntü erişimi yaklaşımlarında gri seviyeli görseller için etkili bir özellik vektörüdür. Fakat renkli görüntülerde 3 farklı kanalın işlenmesini ve elde edilen bilgilerin birleştirilmesini gerektirir. İlaveten çıkarılan özellik vektörünün boyutunun artması hesapsal maliyeti ve bellek gereksinimini arttıracaktır. Kılıçaslan ve diğerleri söz konusu problemin üstesinden gelmek için renk uzayını bölütleyip tek boyutlu histogram elde eden bir yaklaşım önermişlerdir [22]. Ancak ilgili çalışmada tek eşik ile 8 elemanlı bir histogram elde edilmiştir. Bu çalışmada çok seviyeli eşikleme ile renkli görüntüleri temsil edebilen sınıfsal tabanlı tek boyutlu histogram önerilmiştir. Başlangıçta tekrarlı ortalama yöntemi ile her renk kanalı için elde edilen eşik değerleri aracılığıyla renk uzayı bölümlenmiştir. Başka bir ifade ile üç boyutlu renk uzayı alt prizmalara ayrılmaktadır. Ardından her alt prizmada bulunan pikseller aynı kümeye dâhil edilir. Aynı küme içerisinde bulunan piksellere, o sınıftaki piksellerin ortalama değerleri atanarak renk indirgemesi yapılmaktadır. Alt küplerin sayısı eşik sayısına bağlıdır ve $K=(t+1)^{3}$ şeklinde hesaplanmaktadır. Sonrasında her bir küme $\left\{c_{0}, c_{1}, \ldots, c_{K-1}\right\}$ şeklinde etiketlenmektedir. Şekil 1 tek ve iki eşik kullanılarak bölümlenmiş renk uzayını göstermektedir.

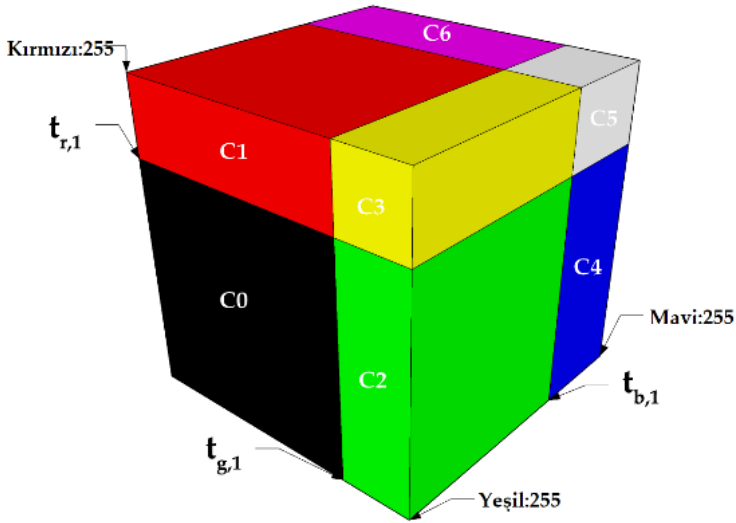

(a)

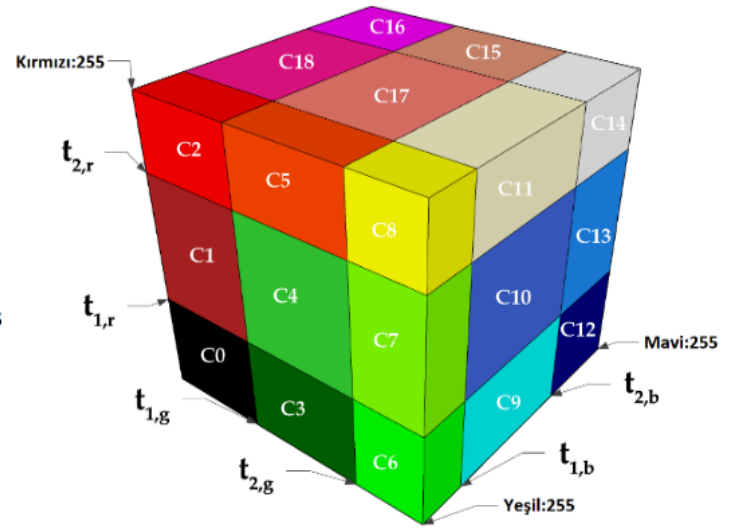

(b)

Şekil 1. Bölümlenmiş renk uzayı a) $t=1, K=8$ b) $t=2, K=27$.

Renk uzayını tek bir eşik ile bölümlemek için gerekli kurallar ve sınıf etiketleri Tablo 2'de verilmiştir. Tablo 2' deki $t_{r}$, $t_{g}$ ve $t_{b}$, sırasıyla kırmızı, yeşil ve mavi kanallar için hesaplanan eşik değerleridir. Ayrıca, $m_{i}, i$. sınıfa atanan piksel sayısıdır. Bir görüntüdeki toplam piksel sayısı, tüm sınıflardaki piksel sayısının toplamına eşit olacağından, 


$$
M x N=\sum_{i=0}^{7} m_{i}
$$

ifadesi yazılabilir. Bu durumda bir pikselin herhangi bir sınıfta olma olasılığ ise

$$
p_{i}=\frac{m_{i}}{M \times N}
$$

şeklinde hesaplanmaktadır.

Tablo 2. Tek eşik ile renk uzayının bölümlenmesi

\begin{tabular}{cccc}
\hline Sinıf etiketi & Bölümleme kuralları & Sinıftaki piksel sayısı & İkili kodu \\
\hline$c_{0}$ & Eğer $\left(R<=t_{r} \& G<=t_{g} \& B<=t_{b}\right)$ & $m_{0}$ & 000 \\
$c_{1}$ & Ĕğr $\left(R<=t_{r} \& G<=t_{g} \& B>=t_{b}\right)$ & $m_{1}$ & 001 \\
$c_{2}$ & Ĕger $\left(R<=t_{r} \& G>=t_{g} \& B<=t_{b}\right)$ & $m_{2}$ & 010 \\
$c_{3}$ & Ĕğr $\left(R<=t_{r} \& G>=t_{g} \& B>=t_{b}\right)$ & $m_{3}$ & 011 \\
$c_{4}$ & Eğer $\left(R>=t_{r} \& G<=t_{g} \& B<=t_{b}\right)$ & $m_{4}$ & 100 \\
$c_{5}$ & Ĕger $\left(R>=t_{r} \& G<=t_{g} \& B>=t_{b}\right)$ & $m_{5}$ & 101 \\
$c_{6}$ & Ĕger $\left(R>=t_{r} \& G>=t_{g} \& B<=t_{b}\right)$ & $m_{6}$ & 110 \\
$c_{7}$ & Ĕğer $\left(R>=t_{r} \& G>=t_{g} \& B>=t_{b}\right)$ & $m_{7}$ & 111 \\
\hline
\end{tabular}

Şekil 2 (a), görüntü erişiminde sıklıkla kullanılan Corel1K veri setinden rastgele seçilmiş Sahil görüntüsüne aittir. Şekil 2 (b) ise orijinal görüntünün 3 boyutlu uzayda renk dağılımını göstermektedir. Şekil 3 (a) ve Şekil 3 (b) ise, sırasıyla ilgili görüntünün 2 eşik kullanılarak 27 kümeli indirgenmiş halini ve ona ait renk dağılımını göstermektedir. Şekil 3 incelendiğinde sahil görüntüsünün daha az renkle temsil edildiği görülmektedir. Renk dağılımındaki kürelerin büyüklüğü sınıflara atanan piksellerin sayısı ile doğru orantılıdır. Birbirine yakın renkler aynı küme altında toplanarak renk indirgemesi yapıldığ açıktır. Sahil görüntüsünün üç kanallı histogramı, Şekil 4'te gösterilmiştir. Şekil 4'te gösterilen histogram, İTGE için bir özellik vektörü olarak kullanılabilir. Ancak üç renk kanalını içeren bilgilerin işlenmesi ve anlamlı bir şekilde birleştirilmesi problemdir. Diğer taraftan üç boyutlu dizi ile temsil edilen renkli histogramın işlenmesinin hesapsal maliyeti ve bellek gereksinimi oldukça fazladır. Dolayısıyla renkli görüntülerin kabul edilebilir bilgi kayıpları ile daha az renkle temsil edilebilmesi yani renk indirgemesi yapılması vazgeçilemez bir süreçtir. Bu çalışmada indirgenmiş görüntülerin Eşt. 10'da tanımlanan tek boyutlu histogramı görüntü erişimi için kullanılabilecek alternatif bir yöntem olarak önerilmiştir. Sahil görüntüsünün tek eşikli ve sekiz sınıflı histogramı Şekil 5'te, iki eşikli ve 27 sınıflı histogramı Şekil 6'da gösterilmiştir. Söz konusu histogramlar indirgenmiş görüntüleri temsil eden dağılımlardır. Bununla birlikte indirgenen görüntülerde bilgi kaybı yaşanması muhtemel bir durumdur. Renk indergeme işlemi sonucunda elde edilen görüntü ile orijinal görüntü arasındaki benzerlik, tepe sinyal gürültü oranı (peak signal noise ratio: PSNR) ve yapısal benzerlik (structural similarity: SSIM) metrikleri ile değerlendirilmiştir. Sahil görüntüsü üzerinde 1,2 ve 3 seviyeli eşikler kullanılarak elde edilen ortalama PSNR ve SSIM sonuçları Tablo 3'te verilmiştir. Tablo 3'den anlaşılacağı gibi, indirgenen görüntüdeki bilgi kaybı eşik sayısı arttıkça azalmaktadır. Başka bir ifade ile orijinal görüntüyü daha iyi temsil eden indirgenmiş görüntüler elde edilmiştir. 


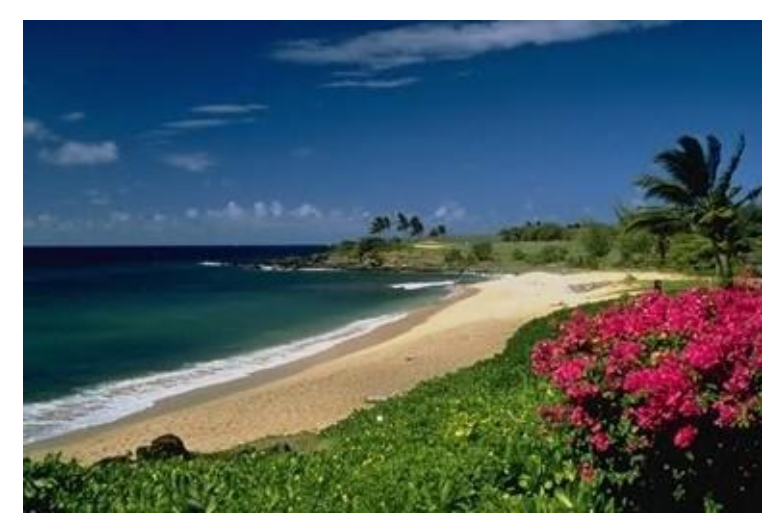

(a)

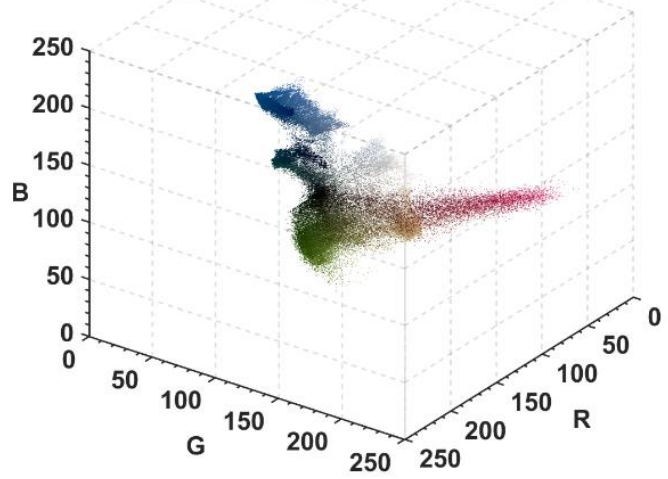

(b)

Şekil 2. Sahil (a) Orijinal (b) Renk dă̆ılımı

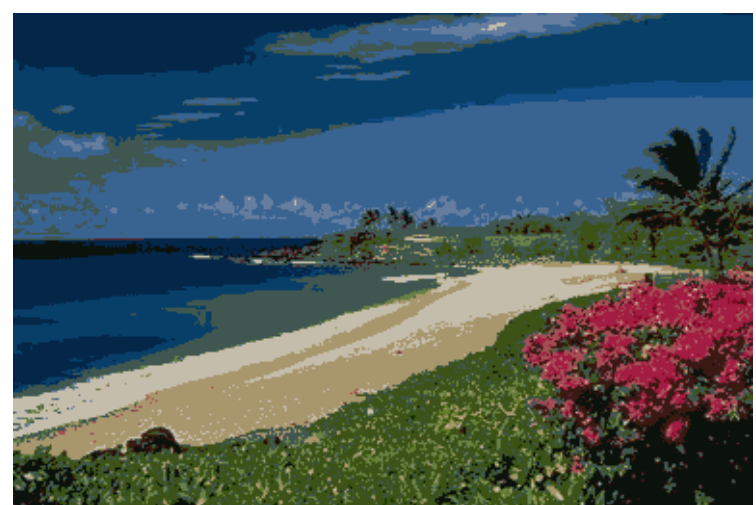

(a)

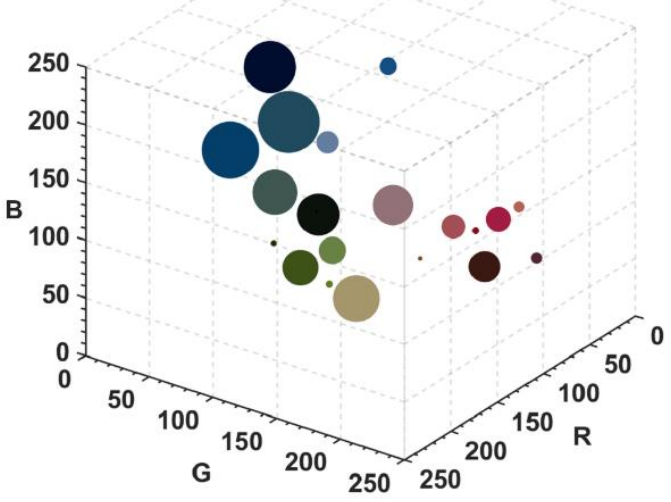

(b)

Şekil 3. Sahil: indirgenmiş (a) $t=2, K=27$ (b) Renk dağılımı

Tablo 3. Sahil: SSIM ve PSNR sonuçları

\begin{tabular}{llll}
\hline \multicolumn{2}{c}{ Eșik sayıları ve değerleri } & SSIM & PSNR \\
\hline 1 (R:66; $\quad$ G:84 ; & B:91) & 0,855 & 20,228 \\
2 (R:25, $125 ; \quad$ G:51, $120 ; \quad$ B:42, 130) & 0,951 & 23,670 \\
3 (R:25, 66, 125; G:51, 84, 120; $\mathrm{B}: 42,91,130)$ & 0,979 & 27,151 \\
\hline
\end{tabular}




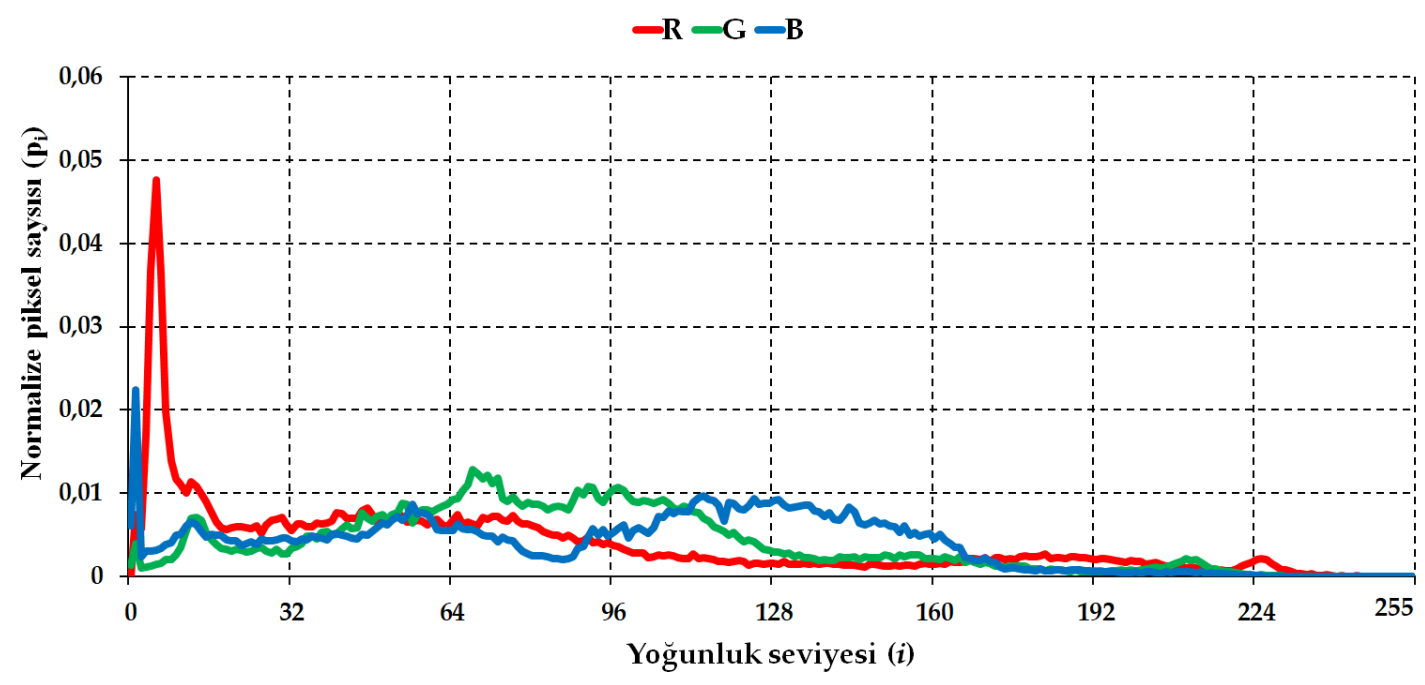

Şekil 4. Sahil: histogramları

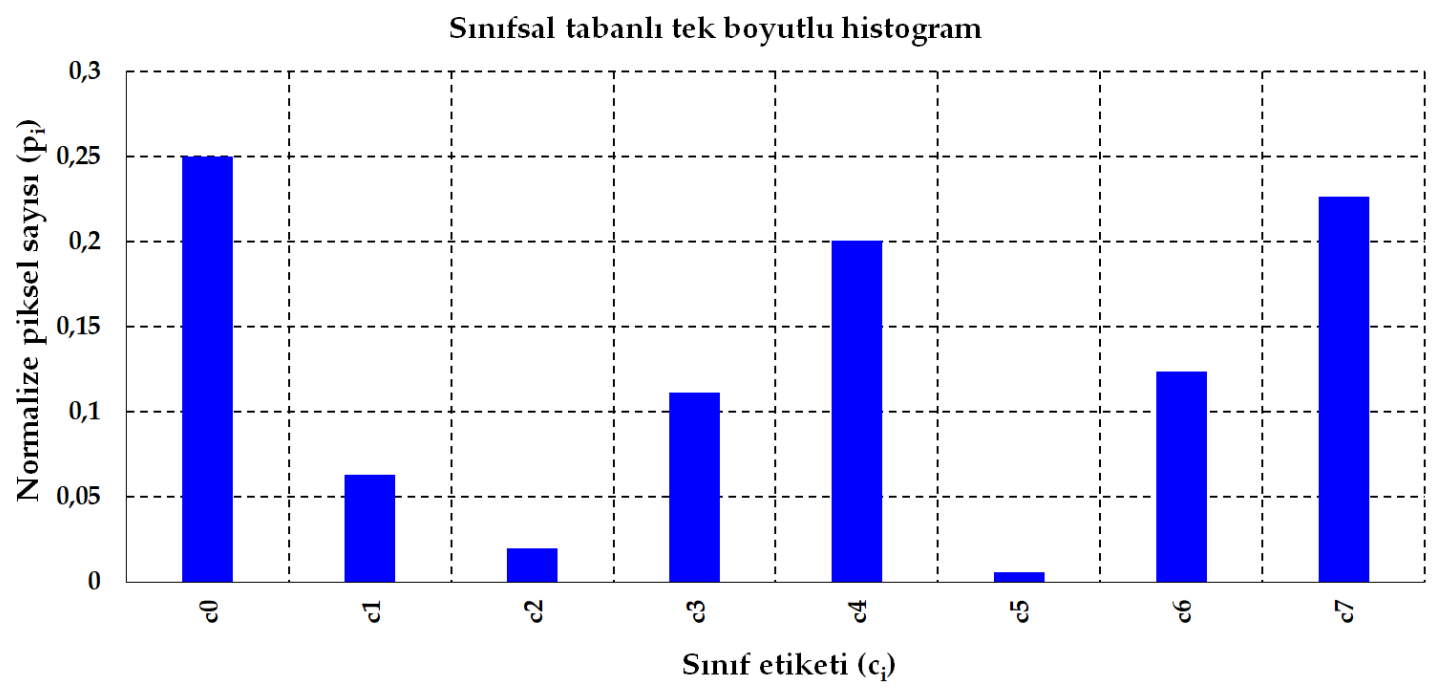

Şekil 5. Sahil: 8 kümeli histogramı

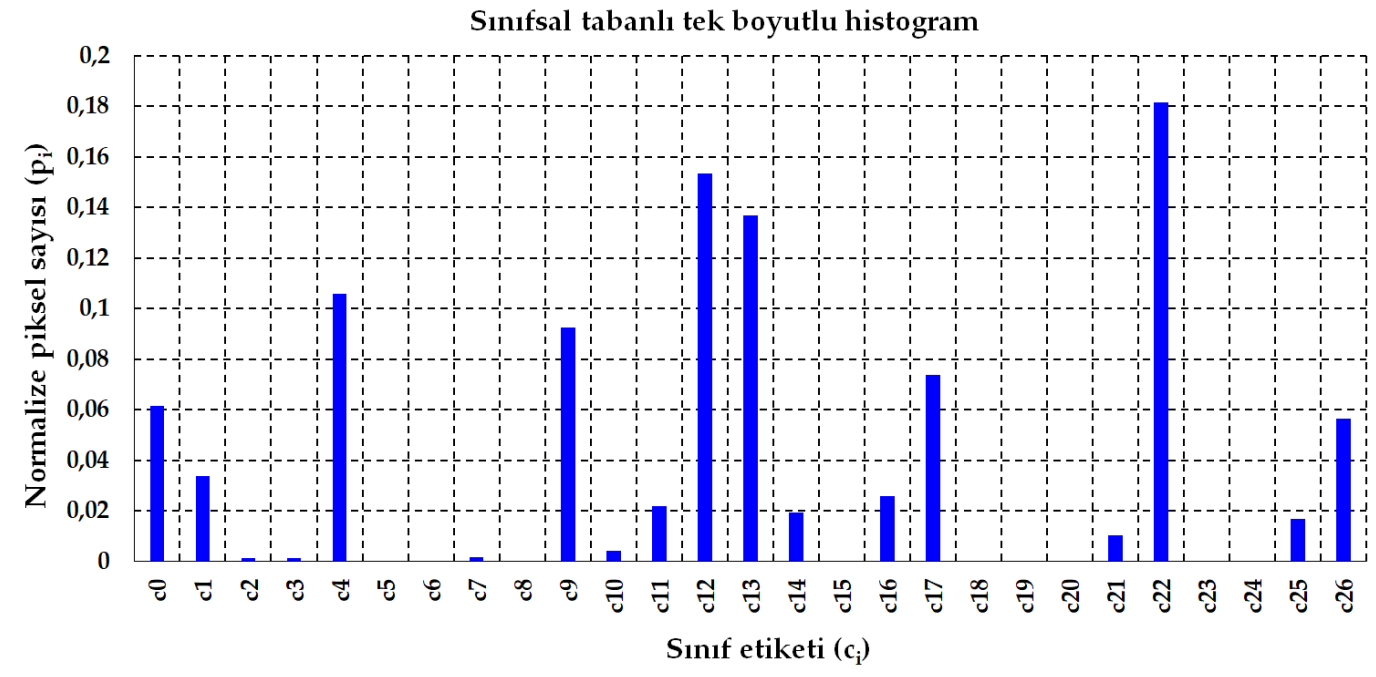

Şekil 6. Sahil: 27 kümeli histogramı 


\section{TEK BOYUTLU HísTOGRAM İLE GöRÜNTÜ ERIȘiMi}

Görüntü erişim uygulamalarında histogramın özellik vektörü olarak kullanılması yaygındır. Ancak gri seviyeli görüntülerde tek bir kanal üzerinden işlem yapılırken, renkli görüntülerde üç farklı histogram bilgisi işlenmektedir. Bu sebeple, renkli görüntüler için özellik vektörünün elde edilmesinde yüksek hesaplama maliyeti gerekmektedir. Bu çalışmada renkli görüntülerin tek boyutlu renk histogramı kullanılarak yeni bir içerik tabanlı görüntü erişim algoritması geliştirilmiştir. İlgili algoritmada ise üç farklı histogramın veya üç boyutlu renkli histogramın işlenmesine gerek kalmamıştır. Böylelikle hesaplama maliyeti de düşürülmüştür. Geliştirilen algoritmanın aşamalarını gösteren blok diyagramı Şekil 7'de verilmiştir.

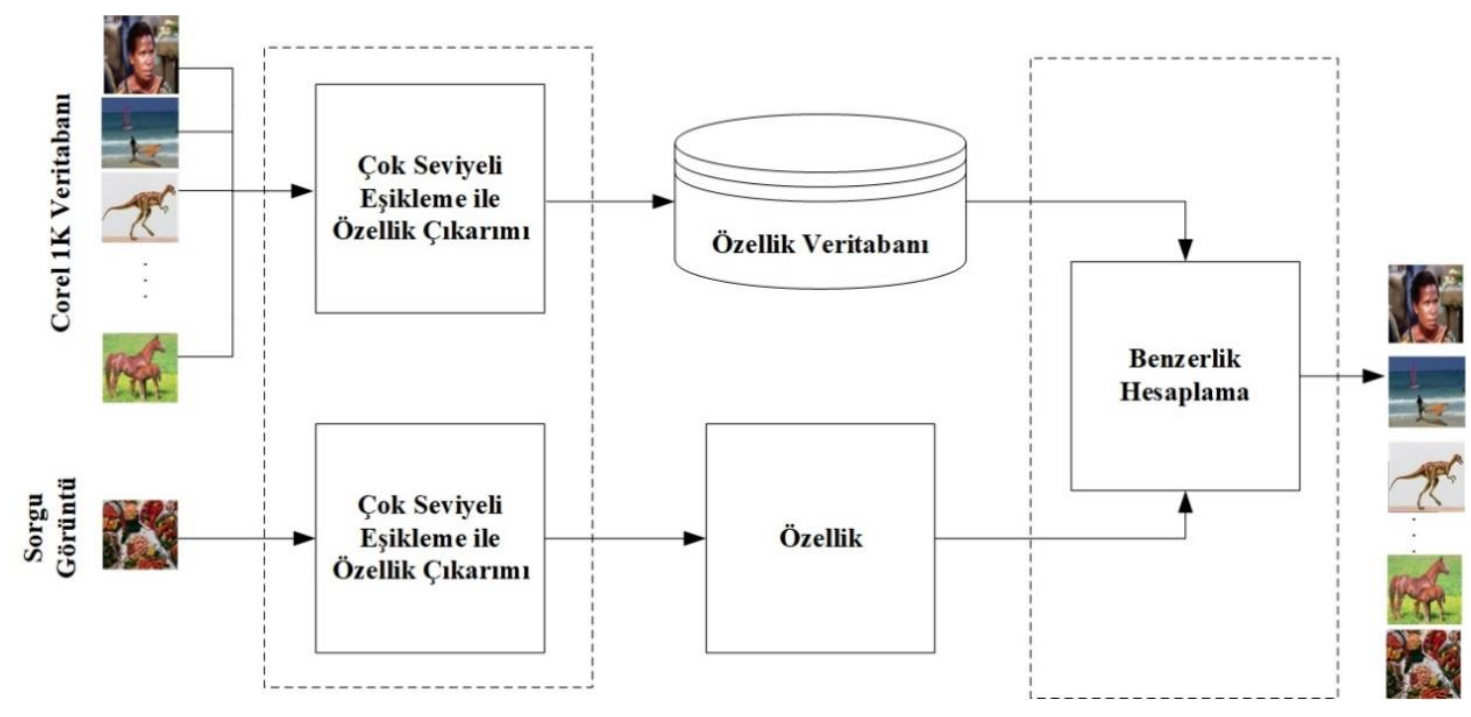

Şekil 7. Önerilen yaklaşımın blok diyagramı

Önerilen İTGE sisteminin benzerlik hesaplama aşamasında histogramların kesişimi (intersection) ve kosinüs benzerliği yöntemlerinden yararlanılmıştır. Histogram kesişimi kısmi eşleştirmeler yapan bir metrik olup;

$$
d_{\text {int }}\left(p_{\alpha}, p_{\beta}\right)=\sum_{i=0}^{K} \min \left(p_{\alpha, i}, p_{\beta, i}\right)
$$

şeklinde hesaplanmaktadır. Eşt. 11 deki $p_{\alpha}$ ve $p_{\beta}$ sırasıyla sorgulanan ve veri tabanındaki kayıtlı herhangi bir görüntünün histogramını, $i$ ise tek boyutlu histogramdaki renk indislerini ifade etmektedir. Görüntü benzerliğini hesaplamasında kullanılan kosinüs yaklaşımı ise,

$$
d_{\cos }\left(p_{\alpha}, p_{\beta}\right)=\frac{\sum_{i=0}^{K} p_{\alpha, i} p_{\beta, i}}{\sqrt{\sum_{i=0}^{K} p_{\alpha, i}^{2}} \sqrt{\sum_{i=0}^{K} p_{\beta, i}^{2}}}
$$

şeklinde tanımlanmıştır. Eşt. 12 de verilen $d_{c o s}\left(p_{\alpha}, p_{\beta}\right)$ ifadesinin bire eşit olması karşılaştırılan görüntülerin aynı olduğu anlamına gelmektedir. 


\section{Deneysel Sonuclar Ve Yorumlar}

Deneysel sonuçlar elde etmek için referans veri seti olan Corel1K kullanılmıştır. İlgili veri setinin içerisinde 10 farklı kategori ve her kategoride 100 adet görüntü bulunmaktadır. Şekil 6 Corel1K'nın kategorilerinden alınan tipik görüntüleri göstermektedir. Önerilen yöntemin performans değerlendirmesinde ise, LBG algoritması ile yapılan erişim sonuçlarından yararlanılmıştır. Geliştirilen yaklaşımda 3 seviyeli eşikleme yapılarak 64 elemanlı özellik vektörü çıkarıldığından, LBG algoritmasında da karşılaştırmalardaki tutarlılık adına $K=64$ küme kullanılmıştır.

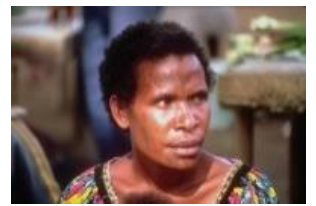

(a)

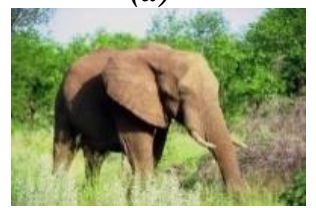

$(f)$

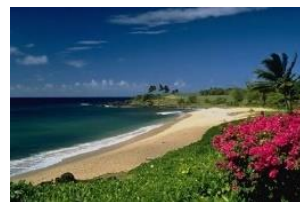

(b)

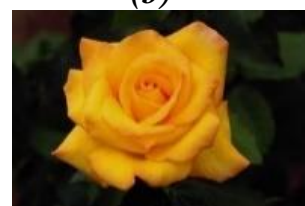

(g)

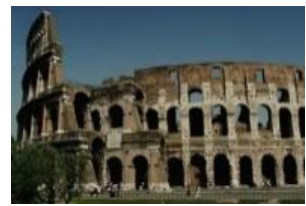

(c)

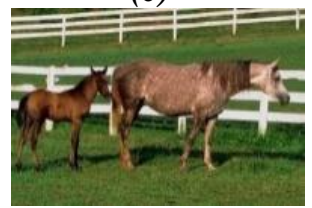

(h)

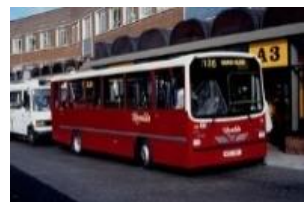

(d)

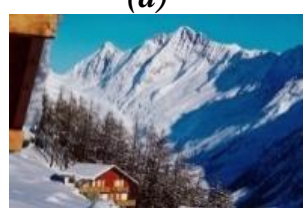

(l)

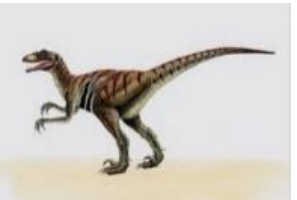

$(e)$

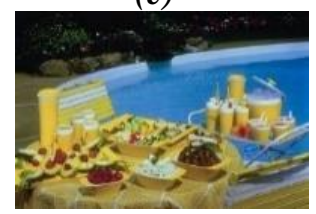

(i)

Şekil 8. Corel $1 K$ veri seti (a) Afrikalılar (b) Sahiller (c) Yapttlar (d) Otobüsler (e) Dinozorlar (f) Filler (g) Çiçekler (h) Atlar (i) Dağlar (i) Yiyecekler

Şekil 8'de de görüldüğü gibi deneysel bulgularda kullanılan veri setinde çok sayıda kategori olduğundan performans değerlendirmesinde çok sınıflı karışıklık matrisi tercih edilmiştir. Tablo 4 çok sınıflı genelleştirilmiş karışıklık matrisini göstermektedir. Söz konusu matriste satır bilgileri sorgulanan nesnelerin gerçek sınıflarını, sütunlarsa sorgulama sonucunda tahmin edilen sınıfları göstermektedir. Matrisin köşegeni doğru sınıflandırılan görüntü sayılarını ifade ederken, köşegen dışında kalan diğer hücreler yanlış sınıflandırılan nesne sayısını temsil etmektedir [23]. Matristeki $X$ tüm örneklerin sayısı olup,

$$
X=\sum_{g=1}^{G} \sum_{f=1}^{G} Z_{g f}
$$

şeklinde bulunmaktadır. Eşt. 13 te $G, g, f$ değerleri sırasıyla sınıf sayısını, gerçekteki nesne sınıflarını ve tahmin edilen nesne sinıflarını göstermektedir. $z_{g f}$ ise hücreleri ifade etmektedir [23]. İlaveten $g$ sınıfında olduğu tahmin edilen nesnelerin sayısı,

$$
X_{g}=\sum_{f=1}^{G} Z_{g f}
$$

ifadesi ile hesaplanmaktadır. Eşt. 14 deki $z_{\alpha f}$ gerçekte $g$ sınıfında fakat $f$ sınıfında tahmin edilen örneklerin sayısını temsil etmektedir [23]. Sorgu sonucunda $g$. sinıfta tahmin edilen örnek sayısı ise

$$
X_{g}^{\prime}=\sum_{f=1}^{G} Z_{f g}
$$

şeklinde ifade edilmektedir [23]. Burada $z_{f g}$ gerçekte $f$ sınıfında olan fakat $g$ sınıfında olduğu tahmin edilen nesnelerin sayısını göstermektedir. Algoritmaların sınıf bazındaki performansını rahatlıkla değerlendirebileceğimiz karışıklık matrisi, ayrıca global başarım ölçümünü de göstermektedir. Sınıf 
temelli değerlendirme için ilgili sınıfa ait kesinlik (precision: $\mathrm{P}$ ) ve hassasiyet (recall: $\mathrm{R}$ ) değerlerine bakılmakta olup, söz konusu değerler,

$$
\begin{gathered}
P_{g}=\frac{Z_{g g}}{X_{g}^{\prime}} \\
R_{g}=\frac{Z_{g g}}{X_{g}}
\end{gathered}
$$

şeklinde gösterilmektedir [23]. Eşt. 16'da, $P_{g} g$. sınıfa ait kesinlik değerini, $z_{g g} g$. sinıfta olan ve doğru olarak tahmin edilen örnek sayısını ifade etmektedir. Ayrıca $x_{g}^{\prime} g$. sınıfta tahmin edilen örnek sayısının toplamını göstermektedir. Eşt. 17 ise $R_{g} g$ indisli sınıfa ait olan hassasiyeti ve $\mathrm{x}_{g}$ gerçekte $g$. sınıfta yer alan örneklerin sayısını göstermektedir. İTGE tekniklerin sınıflandırma performanslarının genel başarısı başka bir ifade ile doğruluğu (accuracy: $A_{G}$ ) ise

$$
A_{G}=\frac{\sum_{g=1}^{G} z_{g g}}{X}
$$

şeklinde hesaplanmaktadır [23]. Ayrıca çok seviyeli karışıklık matrisinde bütün sınıflardaki başarı ortalaması alınarak genel başarı durumları için makro kesinlik $P_{M}$ ve makro hassasiyet $R_{M}$ değerleri,

$$
\begin{array}{r}
P_{M}=\frac{\sum_{g=1}^{G} P_{g}}{G} \\
R_{M}=\frac{\sum_{g=1}^{G} R_{g}}{G}
\end{array}
$$

\begin{tabular}{|c|c|c|c|c|c|c|c|c|}
\hline & & \multicolumn{5}{|c|}{ Tahmin edilen sınıflar } & \multirow{2}{*}{$x_{g}$} & \multirow{2}{*}{$R_{g}$} \\
\hline & & 1 & 2 & 3 & $\ldots$ & $G$ & & \\
\hline \multirow{5}{*}{ 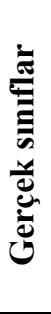 } & 1 & $z_{11}$ & $z_{12}$ & $z_{13}$ & $\ldots$ & $z_{1 G}$ & $x_{1}$ & $R_{1}$ \\
\hline & 2 & $z_{21}$ & $z_{22}$ & $z_{23}$ & $\ldots$ & $z_{2 G}$ & $x_{2}$ & $R_{2}$ \\
\hline & 3 & $z_{31}$ & $z_{32}$ & $z_{33}$ & $\cdots$ & $z_{3 G}$ & $x_{3}$ & $R_{3}$ \\
\hline & $\ldots$ & $\ldots$ & $\ldots$ & $\ldots$ & $\ldots$ & $\ldots$ & $\ldots$ & $\ldots$ \\
\hline & G & $z_{G 1}$ & $z_{G 2}$ & $z_{G 3}$ & $\cdots$ & $z_{G G}$ & $x_{G}$ & $R_{G}$ \\
\hline & $x_{g}$ & $x_{1}^{\prime}$ & $x_{2}^{\prime}$ & $x_{3}$ & $\cdots$ & $x_{G}$ & & \\
\hline & $P_{g}$ & $P_{1}$ & $P_{2}$ & $P_{3}$ & $\ldots$ & $P_{G}$ & & \\
\hline
\end{tabular}

şeklinde bulunmaktadır [23-24].

Tablo 4. G sınıflı karışılklık matrisi

Tablo 5 ve Tablo 6 LBG ile gerçekleştirilen erişim sisteminin performansını temsil eden karışıklık matrislerini göstermektedir. Bahsi geçen tablolarda sırasıyla kosinüs ve histogramların kesişimi tekniği 
kullanıldığındaki başarı durumları bulunmaktadır. Tablo 7 ve Tablo 8'de ise önerilen yaklaşım ile yürütülen görüntü erişiminin başarımı gösterilmiştir. Tablo 7'de söz konusu yaklaşımın kosinüs metriği ve Tablo 8'de histogram kesişimi ile ilgili performans sonuçları bulunmaktadır. Tablolarda bulunan karışıklık matrislerinde yaklaşımların sınıfsal başarı durumları ve genel performansları ayrı ayrı değerlendirilmiştir.

Karışıklık matrislerinin oluşturulmasında sorgu görüntüye en çok benzeyen 20 görüntünün erişimi esas alınmıştır. Corel1 K'da her görüntü sorgu görüntü olarak kullanılıp aynı veri tabandaki 1000 adet görüntü ile karşılaştırılmıştır. Dolayısıyla her kategoride toplamda 2000 adet görüntüye erişilmektedir. Ayrıca, Corel1 K'da 10 kategori olduğundan her karışıklık matrisi için toplamda 20000 adet görüntüye erişim gerçekleştirilmiştir.

Tablo 5, Tablo 6, Tablo 7 ve Tablo 8'deki karışıklık matrisleri incelendiğinde, her iki yöntemde de farklı benzerlik metriklerinin farklı sonuçlar ürettiği görülmektedir. $\mathrm{Bu}$ durum, benzerlik hesaplama algoritmalarının yöntemlerin performansı açısından önemli olduğunun göstergesidir. Algoritmaların başarım durumlarına dikkate alındığında, her iki yöntemde de kesişim benzerliğinin kosinüs benzerliğine göre daha başarılı sonuçlar ürettiği açıktır. Başka bir ifade ile histogram kesişimi kosinüs benzerliğine göre daha ilişkili görüntüler getirmektedir.

Tablo 5. $L B G$ ve kosinüs benzerliği: $P_{M}: 0,2944, R_{M}: 0,2947, A_{G}: 0,2947$

\begin{tabular}{|c|c|c|c|c|c|c|c|c|c|c|c|c|c|}
\hline \multirow{2}{*}{\multicolumn{2}{|c|}{ Kategoriler }} & \multicolumn{10}{|c|}{ Tahmin edilen sınıflar } & \multirow{3}{*}{$\begin{array}{c}\mathbf{x}_{\mathbf{g}} \\
2000\end{array}$} & \multirow{3}{*}{$\begin{array}{c}\mathbf{R}_{\mathbf{g}} \\
0,336\end{array}$} \\
\hline & & \multirow{2}{*}{ 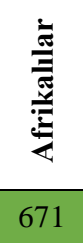 } & \multirow{2}{*}{ 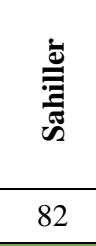 } & \multirow{2}{*}{ 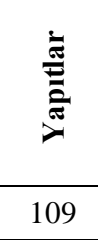 } & \multirow{2}{*}{ 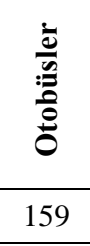 } & \multirow{2}{*}{ 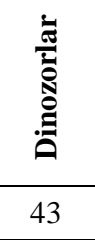 } & \multirow{2}{*}{$\begin{array}{c}\stackrel{\grave{E}}{\grave{E}} \\
202\end{array}$} & \multirow{2}{*}{ 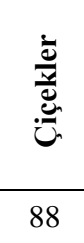 } & \multirow{2}{*}{$\begin{array}{l}\frac{\dot{\Xi}}{幺} \\
117\end{array}$} & \multirow{2}{*}{ 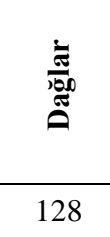 } & \multirow{2}{*}{ 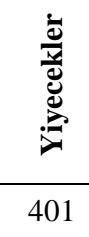 } & & \\
\hline \multirow{12}{*}{ 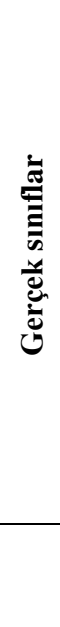 } & Afrikalılar & & & & & & & & & & & & \\
\hline & Sahiller & 163 & 265 & 267 & 46 & 20 & 371 & 100 & 277 & 258 & 233 & 2000 & 0,133 \\
\hline & Yapıtlar & 172 & 229 & 374 & 53 & 40 & 347 & 133 & 204 & 260 & 188 & 2000 & 0,187 \\
\hline & Otobüsler & 568 & 94 & 76 & 272 & 23 & 157 & 94 & 97 & 101 & 518 & 2000 & 0,136 \\
\hline & Dinozorlar & 9 & 7 & 20 & 38 & 1846 & 44 & 3 & 0 & 3 & 30 & 2000 & 0,923 \\
\hline & Filler & 168 & 203 & 216 & 40 & 135 & 533 & 27 & 110 & 262 & 306 & 2000 & 0,267 \\
\hline & Çiçekler & 308 & 140 & 280 & 116 & 5 & 135 & 438 & 219 & 179 & 180 & 2000 & 0,219 \\
\hline & Atlar & 199 & 207 & 226 & 27 & 0 & 233 & 115 & 655 & 177 & 161 & 2000 & 0,328 \\
\hline & Dağlar & 198 & 210 & 320 & 50 & 55 & 383 & 116 & 169 & 291 & 208 & 2000 & 0,146 \\
\hline & Yiyecekler & 467 & 95 & 94 & 202 & 94 & 212 & 106 & 78 & 104 & 548 & 2000 & 0,274 \\
\hline & $\mathbf{x}_{\mathbf{g}}^{\prime}$ & 2923 & 1532 & 1982 & 1003 & 2261 & 2617 & 1220 & 1926 & 1763 & 2773 & & \\
\hline & $\mathbf{P}_{\mathrm{g}}$ & 0,23 & 0,173 & 0,189 & 0,271 & 0,817 & 0,204 & 0,359 & 0,34 & 0,1651 & 0,198 & & \\
\hline
\end{tabular}


Tablo 6. LBG ve histogram kesişimi: $P_{M}: 0,3219, R_{M}: 0,3093, A_{G}: 0,3093$

\begin{tabular}{|c|c|c|c|c|c|c|c|c|c|c|c|c|c|}
\hline & & \multicolumn{10}{|c|}{ Tahmin edilen sınıflar } & \multirow[b]{2}{*}{$\mathbf{x}_{\mathbf{g}}$} & \multirow[b]{2}{*}{$\mathbf{R}_{\mathbf{g}}$} \\
\hline & & 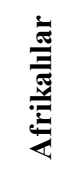 & 离 & 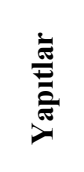 & 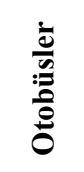 & 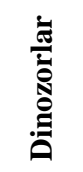 & 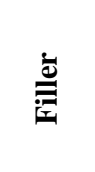 & 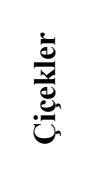 & $\frac{\Xi}{E}$ & 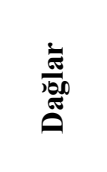 & $\frac{\grave{d}}{\stackrel{d}{d}}$ & & \\
\hline \multirow{12}{*}{ 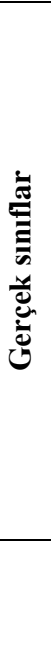 } & Afrikalılar & 671 & 71 & 125 & 156 & 28 & 194 & 70 & 111 & 122 & 452 & 2000 & 0,336 \\
\hline & Sahiller & 175 & 281 & 248 & 53 & 9 & 356 & 71 & 276 & 263 & 268 & 2000 & 0,141 \\
\hline & Yapitlar & 203 & 185 & 438 & 38 & 10 & 361 & 121 & 164 & 291 & 189 & 2000 & 0,219 \\
\hline & Otobüsler & 600 & 90 & 83 & 276 & 7 & 144 & 73 & 88 & 105 & 534 & 2000 & 0,138 \\
\hline & Dinozorlar & 12 & 4 & 17 & 24 & 1830 & 72 & 2 & 0 & 12 & 27 & 2000 & 0,915 \\
\hline & Filler & 212 & 199 & 245 & 34 & 82 & 530 & 29 & 111 & 257 & 301 & 2000 & 0,265 \\
\hline & Çiçekler & 312 & 124 & 304 & 95 & 4 & 163 & 429 & 169 & 212 & 188 & 2000 & 0,215 \\
\hline & Atlar & 183 & 207 & 170 & 27 & 2 & 252 & 100 & 694 & 180 & 185 & 2000 & 0,347 \\
\hline & Dağlar & 228 & 183 & 349 & 57 & 28 & 363 & 104 & 129 & 317 & 242 & 2000 & 0,159 \\
\hline & Yiyecekler & 450 & 88 & 92 & 135 & 32 & 223 & 72 & 81 & 108 & 719 & 2000 & 0,36 \\
\hline & $\mathbf{x}_{\mathbf{g}}^{\prime}$ & 3046 & 1432 & 2071 & 895 & 2032 & 2658 & 1071 & 1823 & 1867 & 3105 & & \\
\hline & $\mathbf{P}_{\mathbf{g}}$ & 0,22 & 0,196 & 0,212 & 0,308 & 0,901 & 0,199 & 0,401 & 0,381 & 0,1698 & 0,232 & & \\
\hline
\end{tabular}

Tablo 7. Önerilen yöntem ve kosinüs benzerliği: $P_{M}: 0,5212, R_{M}: 0,5176, A_{G}: 0,5176$

\begin{tabular}{|c|c|c|c|c|c|c|c|c|c|c|c|c|c|}
\hline \multirow{2}{*}{\multicolumn{2}{|c|}{ Kategoriler }} & \multicolumn{10}{|c|}{ Tahmin edilen sınıflar } & \multirow{3}{*}{$\begin{array}{c}\mathbf{x}_{\mathbf{g}} \\
2000\end{array}$} & \multirow{3}{*}{$\begin{array}{c}\mathbf{R}_{\mathbf{g}} \\
0,632\end{array}$} \\
\hline & & 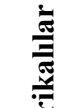 & $\stackrel{\grave{e}}{=}$ & $\stackrel{\grave{\Xi}}{\bar{E}}$ & 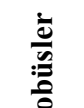 & 预 & $\stackrel{\grave{\Xi}}{=}$ & $\frac{\bar{d}}{\frac{\pi}{d}}$ & 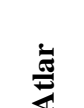 & 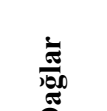 & $\frac{\dot{y}}{\frac{x}{2}}$ & & \\
\hline \multirow{12}{*}{ 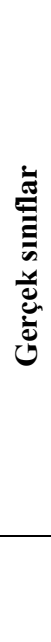 } & Afrikalılar & 1264 & 57 & 244 & 76 & 5 & 86 & 13 & 19 & 71 & 165 & & \\
\hline & Sahiller & 157 & 555 & 364 & 94 & 9 & 230 & 21 & 87 & 348 & 135 & 2000 & 0,278 \\
\hline & Yapitlar & 322 & 229 & 719 & 124 & 4 & 175 & 74 & 19 & 229 & 105 & 2000 & 0,360 \\
\hline & Otobüsler & 396 & 115 & 246 & 737 & 3 & 98 & 57 & 23 & 199 & 126 & 2000 & 0,369 \\
\hline & Dinozorlar & 0 & 1 & 0 & 19 & 1920 & 45 & 0 & 0 & 0 & 15 & 2000 & 0,960 \\
\hline & Filler & 213 & 104 & 327 & 92 & 23 & 797 & 29 & 91 & 156 & 168 & 2000 & 0,399 \\
\hline & Çiçekler & 105 & 28 & 101 & 104 & 2 & 41 & 1143 & 181 & 57 & 238 & 2000 & 0,572 \\
\hline & Atlar & 48 & 33 & 15 & 26 & 1 & 58 & 70 & 1663 & 62 & 24 & 2000 & 0,832 \\
\hline & Dağlar & 180 & 349 & 365 & 184 & 13 & 186 & 36 & 42 & 482 & 163 & 2000 & 0,241 \\
\hline & Yiyecekler & 304 & 46 & 99 & 56 & 48 & 77 & 145 & 30 & 124 & 1071 & 2000 & 0,536 \\
\hline & $\mathbf{x}_{g}^{\prime}$ & 2989 & 1517 & 2480 & 1512 & 2028 & 1793 & 1588 & 2155 & 1728 & 2210 & & \\
\hline & $\mathbf{P}_{\mathrm{g}}$ & 0,423 & 0,366 & 0,29 & 0,487 & 0,947 & 0,445 & 0,72 & 0,772 & 0,2789 & 0,485 & & \\
\hline
\end{tabular}


Tablo 8. Önerilen yöntem ve histogram kesişimi: $P_{M}: 0,5459, R_{M}: 0,5372, A_{G}: 0,5372$

\begin{tabular}{|c|c|c|c|c|c|c|c|c|c|c|c|c|c|}
\hline \multirow{2}{*}{\multicolumn{2}{|c|}{ Kategoriler }} & \multicolumn{10}{|c|}{ Tahmin edilen sınıflar } & \multirow{3}{*}{ 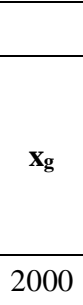 } & \multirow{3}{*}{$\begin{array}{c}\mathbf{R}_{\mathbf{g}} \\
0,633\end{array}$} \\
\hline & & \multirow{2}{*}{ 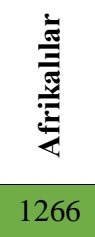 } & \multirow{2}{*}{ 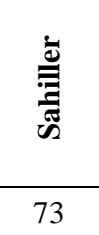 } & \multirow{2}{*}{ 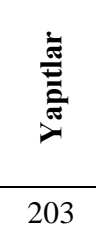 } & \multirow{2}{*}{$\begin{array}{l}\frac{\grave{0}}{\overline{0}} \\
: \frac{0}{0} \\
0\end{array}$} & \multirow{2}{*}{ 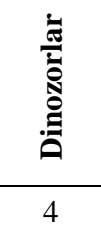 } & \multirow{2}{*}{ 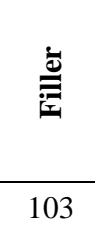 } & \multirow{2}{*}{ 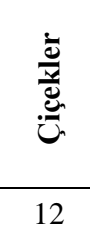 } & \multirow{2}{*}{$\begin{array}{l}\frac{5}{*} \\
30\end{array}$} & \multirow{2}{*}{ 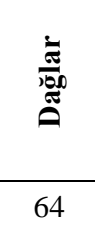 } & \multirow{2}{*}{ 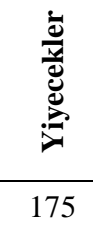 } & & \\
\hline \multirow{12}{*}{ 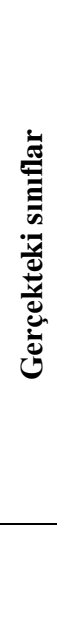 } & Afrikalılar & & & & & & & & & & & & \\
\hline & Sahiller & 182 & 573 & 366 & 86 & 3 & 228 & 22 & 60 & 355 & 125 & 2000 & 0,287 \\
\hline & Yapitlar & 271 & 236 & 835 & 88 & 7 & 208 & 53 & 8 & 217 & 77 & 2000 & 0,418 \\
\hline & Otobüsler & 405 & 117 & 202 & 822 & 10 & 103 & 29 & 20 & 194 & 98 & 2000 & 0,411 \\
\hline & Dinozorlar & 0 & 0 & 2 & 10 & 1924 & 53 & 0 & 0 & 2 & 9 & 2000 & 0,962 \\
\hline & Filler & 193 & 94 & 301 & 67 & 26 & 872 & 34 & 108 & 149 & 156 & 2000 & 0,436 \\
\hline & Çiçekler & 132 & 38 & 118 & 118 & 4 & 54 & 1102 & 182 & 52 & 200 & 2000 & 0,551 \\
\hline & Atlar & 53 & 19 & 10 & 24 & 0 & 56 & 66 & 1707 & 30 & 35 & 2000 & 0,854 \\
\hline & Dağlar & 173 & 364 & 386 & 154 & 4 & 202 & 28 & 27 & 522 & 140 & 2000 & 0,261 \\
\hline & Yiyecekler & 370 & 34 & 84 & 49 & 21 & 83 & 94 & 35 & 109 & 1121 & 2000 & 0,561 \\
\hline & $\mathbf{x}_{\mathbf{g}}^{\prime}$ & 3045 & 1548 & 2507 & 1488 & 2003 & 1962 & 1440 & 2177 & 1694 & 2136 & & \\
\hline & $\mathbf{P g}$ & 0,416 & 0,370 & 0,333 & 0,552 & 0,961 & 0,444 & 0,765 & 0,784 & 0,308 & 0,525 & & \\
\hline
\end{tabular}

Sınıf bazlı kesinlik ve hassasiyet değerlerine göre, Dinozorlar sınıfı hem LBG hem de önerilen algoritmada en başarılı olmuştur. Dinozorlar sınıfının kesinlik değeri histogramların kesişim yaklaşımı ile 0,961, kosinüs benzerliği ile 0,947 olmuştur. Aynı sınıf için LBG ile alınan sonuçlar sırasıyla 0,901 ve 0,817 dir. Başka bir ifade ile geliştirilen yaklaşım Dinozorlar sınıfında LBG den daha başarılı olmuştur. Geliştirilen yöntemin hassasiyet değerleri incelendiğinde her iki benzerlik metriğinde de en başarılı ilk üç kategori Dinozorlar, Atlar ve Afrikalılar olmuştur. LBG ile gerçekleştirilen erişim sistemlerinin hassasiyet değerlerine bakıldığında, kosinüste Dinozorlar, Afrikalılar ve Atlar iken, kesişimde ise Dinozorlar, Yiyecekler ve Atlar en başarılı sınıflar olmuştur. Söz konusu farklılık ilgili yöntemin benzerlik metriğinden daha fazla etkilendiğinin açık göstergesidir. Kesinlik değerleri açısından bakıldığında, algoritmaların en çok zorlandığı kategori ise Dağlar olmuştur. Dağlar sınıfındaki tekrarlı ortalama ve kesişim metriği ile gerçekleştirilen erişim sisteminin başarısı 0,308 iken, LBG'nin aynı benzerlik metriği ile çıktısı 0,1698 mertebesinde kalmıştır. Tablolardaki sınıfsal kesinlik ve hassasiyet değerleri incelendiğinde, önerilen stratejinin her kategoride benzerlik metriği fark etmeksizin LBG'den daha başarılı olduğu açıktır.

İTGE sistemlerinin sınıf düzeyinde başarı durumlarının yanı sıra genel performansları da değerlendirmek önemlidir. $\mathrm{Bu}$ nedenle sistemlerin genel başarı durumlarını makro çıtılarla değerlendirmek gereklidir. Önerilen yöntem historgamların kesişimi metriği ile en başarılı sonuçları üretmiş olup, makro doğruluk değeri, $A_{G}$ 0,5372'dir. Diğer taraftan aynı metrik ile LBG algoritmasının makro doğruluk değeri, $A_{G} 0,3093$ de kalmıştır. Ayrıca kosinüs metriği esas alınarak yapılan deneylere göre, önerilen yöntemin makro doğruluk değeri 0,5176 iken, LBG 'nin makro doğruluk değeri 0,2947 olmuştur. Geliştirilen yöntem hem kosinüs hem de histogramların kesişimi tekniğinde LBG'den daha başarılı olmuştur. Gerek sınıfsal tabanlı ölçütler gerekse de makro performans ölçütlerine göre önerilen yaklaşım LBG den daha başarılı olmuştur. 


\section{SONUC}

Bu çalışmada renkli görüntüler için sınıf tabanlı tek boyutlu histogram kullanan yeni bir görüntü erişimi yaklaşımı önerilmiştir. Başlangıçta renkli görüntüler çok seviyeli tekrarlı ortalama tekniği ile kümelenmiştir. Renk kanallarına ait histogramların ortalamaları eşik hesaplamaları için kullanılmıştır. Ayrıca, eşikleme işleminin sonucu olarak bulunan kümelerin ortalamaları ile renk indirgeme uygulanarak tek boyutlu histogram vektörleri elde edilmiştir. Söz konusu tek boyutlu histogramlar içerik tabanlı görüntü erişim sistemi için bir özellik vektörü olarak değerlendirilmiştir. Önerilen algoritmanın performansı ise bilinen renk indirgeme algoritması olan LBG ile karşılaş̧ırılmışıtır. LBG algoritması, küme merkezlerinin başlangıç değerlerine bağlıdır. Bu nedenle aynı görüntü için farklı özellik vektörleri üretebilmektedir. İlaveten iteratif bir algoritma olan LBG tekniğinde, iterasyonların bitmesini sağlayan ve kullanıcı tarafından belirlenen parametrelere ihtiyaç vardır. Diğer taraftan geliştirilen strateji iteratif değildir. Ayrıca herhangi bir başlangıç değeri ve sonlandırma eşiğine ihtiyaç duymaz. Geliştirilen yaklaşım çok kullanılan iki tane histogram benzerliği ölçüm metodu ile test edilmiştir. Her iki benzerlik metriğinde de LBG'den daha iyi sonuçlar elde edilmiştir.

\section{KAYNAKLAR}

[1] Y. Liu, D. Zhang, G. Lu, and W. Y. Ma, "A survey of content-based image retrieval with highlevel semantics," Pattern recognition, vol. 40, no. 1, pp. 262-282, 2007.

[2] Y. Rui, T.S. Huang, and S.F. Chang, "Image retrieval: Current techniques, promising directions, and open issues,". Journal of visual communication and image representation, vol.10, no. 1, pp. 39-62, 1999.

[3] J.X. Zhou, X.D. Liu, T.W. Xu, J.H. Gan, and W.Q. Liu, "A new fusion approach for content based image retrieval with color histogram and local directional pattern," International Journal of Machine Learning and Cybernetics, vol. 9, no. 4, pp. 677-689, 2018.

[4] H. Tamura and N. Yokoya, "Image database systems: A survey," Pattern Recognition vol. 17 no. 1, pp. 29-43, 1984.

[5] W. Zhou, H. Li and Q. Tian, "Recent advance in content-based image retrieval: A literature survey," arxiv.org, https://arxiv.org/abs/1706.06064, (accessed Nov. 13, 2019).

[6] A.W. Smeulders, M. Worring, S. Santini, A. Gupta, and R. Jain, "Content-based image retrieval at the end of the early years," IEEE Transactions on pattern analysis and machine intelligence, vol. 22, no. 12, pp. 1349-1380, 2000.

[7] R. Biswas, S. Roy and D. Purkayastha, "An efficient content-based medical image indexing and retrieval using local texture feature descriptors," International Journal of Multimedia Information Retrieval, pp. 1-15, 2019.

[8] I. Kunttu, L. Lepisto, J. Rauhamaa, and A. Visa, "Multiscale Fourier descriptor for shape-based image retrieval," In Proceedings of the 17th International Conference on Pattern Recognition, Aug. 2004, pp. 765-768.

[9] A. Karine, A. D. El Maliani and M. El Hassouni, "A novel statistical model for content-based stereo image retrieval in the complex wavelet domain," Journal of Visual Communication and Image Representation, vol. 50, pp. 27-39, 2018. 
[10] B. S. Manjunath, J. R. Ohm, V. V. Vasudevan and A. Yamada, "Color and texture descriptors," IEEE Transactions on circuits and systems for video technology, vol. 11, no. 6, pp. 703-715, 2001.

[11] G. Pass, R. Zabih and J. Miller, "Comparing Images Using Color Coherence Vectors," In ACM multimedia vol. 96, pp. 65-73, 1996.

[12] J. Jing, Q. Li, P. Li and L. Zhang, "A new method of printed fabric image retrieval based on color moments and gist feature description," Textile Research Journal, vol. 86, pp. 1137-1150, 2016.

[13] K. M. Wong, L. M. Po and K. W. Cheung, "A compact and efficient color descriptor for image retrieval," IEEE International Conference on Multimedia and Expo, July 2007, pp. 611-614.

[14] J. Lee and J. Nang, "Content-based image retrieval method using the relative location of multiple ROIs," Advances in Electrical and Computer Engineering, vol. 11, no. 3, pp. 85-90, 2011.

[15] H. Zhao, Q. Li and P. Liu, "Hierarchical geometry verification via maximum entropy saliency in image retrieval," Entropy, vol. 16, pp. 3848-3865, 2014.

[16] R. Ashraf, K. Bashir, A. Irtaza and M. T. Mahmood, "Content based image retrieval using embedded neural networks with bandletized regions," Entropy, vol. 17, pp. 3552-3580, 2015.

[17] X. Lu, J. Wang, X. Li, M. Yang and X. Zhang, "An adaptive weight method for image retrieval based multi-feature fusion," Entropy, vol. 20 pp. 577, 2018.

[18] J. Zhou, X. Liu, W. Liu and J. Gan, "Image retrieval based on effective feature extraction and diffusion process," Multimedia Tools and Applications, vol. 78, no. 5, pp. 6163-6190, 2019.

[19] S. O. Abter and N. A. Abdullah, "An efficient color quantization using color histogram," In New Trends in Information \& Communications Technology Applications, March 2017, ss 13-17.

[20] K. Chiranjeevi and U. R. Jena, "Image compression based on vector quantization using cuckoo search optimization technique," Ain Shams Engineering Journal, vol. 9, no. 4, pp. 1417-1431, 2018.

[21] R. Demirci ve Ü. Okur, "Renkli Görüntülerin Ortalama Tabanlı Çok Seviyeli Eşiklenmesi," Düzce Üniversitesi Bilim ve Teknoloji Dergisi, c. 7, s. 1, ss. 664-676, 2019.

[22] M. K1lıçaslan, U. Tanyeri ve R. Demirci, "Renkli Görüntüler İçin Tek Boyutlu Histogram," Düzce Üniversitesi Bilim ve Teknoloji Dergisi, c. 6, s. 4, ss. 1094-1107, 2018.

[23] D. Ballabio, F. Grisoni and R. Todeschini, "Multivariate comparison of classification performance measures," Chemometrics and Intelligent Laboratory Systems, vol. 174, pp. 33-44, 2018.

[24] M. Sokolova and G. Lapalme, "A systematic analysis of performance measures for classification tasks," Information Processing and Management, vol. 45, no. 4, pp. 427-437, 2009. 